\title{
Artificial Neural Network Modeling of Job Satisfaction: A Case Study of ICT, Federal University of Agriculture, Makurdi
}

\author{
K. K. Ikpambese \\ Department of Mechanical \\ Engineering, University of \\ Agriculture, P.M.B. 2373 \\ Makurdi-Nigeria
}

\author{
T. D. Ipilakyaa \\ Department of Mechanical \\ Engineering, University of \\ Agriculture, P.M.B. 2373 \\ Makurdi-Nigeria
}

\author{
V. T. Achirgbenda \\ Department of Mechanical \\ Engineering, University of \\ Agriculture, P.M.B. 2373 \\ Makurdi-Nigeria
}

\begin{abstract}
Artificial neural network assessment and modeling of job satisfaction of the Information and Communications Technology (ICT) Directorate workers of Federal University of Agriculture, Makurdi was investigated in this study. Modified Nordic Musculoskeletal Disorder (NMDQ) questionnaires which incorporated health, safety and environment factors were used. The questionnaire consisted of a series of objective questions with 'yes', 'no' and 'I don't know' responses and some were multiple choice questions. Parameters such as health, safety, environment and ergonomic factors were obtained from questionnaires for the modelling of workers efficiency and job satisfaction. The efficiency of workers was determined and normal probability curve for the 40 workers was plotted to identify the outliers. The artificial neural network (ANN) modeling method was employed to predict job satisfaction using health, safety, environment and ergonomic factors as input parameters while job satisfaction was the output. Series of network architectures were considered using different training algorithms. The scale conjugate gradient SCG 4 [3-3] 1 was adopted as the suitable network architecture for predicting job satisfaction. Result indicated that the predicted values of job satisfaction were in the range of $1.42-2.00$ as compared with the actual values of $1.50-2.00$ obtained from the questionnaires. Statistical indicators of normal error (E), used for validation of the model gave minimal errors and varied in the range of $-0.48-$ 0.08 . The plot of the normal probability curve also indicated the presence of outliers or inefficient workers. Whereas most of the workers were satisfied with the existing health, safety, environment (HSE) and ergonomics (E) programs at the work place, some (outliers) were not. The presence of outliers calls for improvement of ergonomic conditions at the ICT directorate.
\end{abstract}

\section{General Terms}

Information and communication technology (ICT), Outliers, Training algorithms

\section{Keywords}

Job satisfaction, health, safety, environment, ergonomics, and artificial neural network

\section{INTRODUCTION}

Ergonomics is the study of human capabilities relating to work demands. Ergonomics also includes examination of human characteristics, capabilities, motivation, and limitations and increasing human efficiency and overall well-being requires necessary design of the living and working environment [1]. When office workstations are designed poorly, it often leads to fatigue, frustration among workers. These workers are rarely the most productive, and often develop costly and painful musculoskeletal (soft tissue) injuries and disorders (MSDs). The rise of computer technology in the workplace over the past decades is astounding. Possibly the greatest oversight with regard to this technology is the way our human bodies interact with the equipment. Johnson et al. [2] reported that computer users in Nigerian universities experience eye strain and neck pain, an average of $71 \%$ Nigerian computer users complain of work related musculoskeletal disorders (WRMD), low back pain, while $69 \%$ complain of finger pain. Nearly $53 \%$ of Computer users in Obafemi Awolowo University in Nigeria experience high ergonomic hazards [3]. Thus this poses serious challenges on overall organizational productivity [4]. Charles [5], observed that at an average level about one billion US dollars is paid yearly as insurance compensation claims to computer workers for WRMD injuries. The above statistics show the enormity of injuries experienced in Computer Workstations $(\mathrm{CW})$. Although the interest and application of ergonomics is growing in developing countries such as Nigeria, the impact is still far from being satisfactory. This trend if not checked will lead to lack of job satisfaction by the workers in such organizations.

Job satisfaction is an area of wide interest to both workers and managers; it is one of the most studied variables in organizational behavior research [6]. It is also a main variable in both research and theory of organizational phenomena ranging from job design to supervision. The traditional model of job focuses on all the feelings that an individual has about his or her job. However, what makes a job pleasing does not depend not only on the nature of the job, but also on the demands of individual against job satisfaction [6]. There is close relationship between health, safety, environment and ergonomics factors (HSEE) relating to job satisfaction. Basically, ergonomics is concerned with all those factors that can affect people and their behavior [7]. Inappropriate design between man and machine leads to decreased safety as faulty system design causes management error. Management error together with work environments harmful factors in turn gives rise to human error. HSEE has defined human factors and ergonomics as the environmental, organizational and job factors, human and individual characteristics which influence behavior at work. Exact consideration of human factors improves health and safety by reducing the number of injuries and cases of ill-health at work. It also provides considerable benefits by decreasing the costs associated with such accidents and enhancing efficiency. 
The uses of advanced statistical methods such as logistic regression, generalized additives models and artificial neural networks (ANN) have being used for modeling of ergonomics versus health, safety and environment (HSE) issues. Artificial neural network (ANN) is an information-processing paradigm that is inspired by the way biological nervous system, such as the brain, processes information. An ANN is configured for a specific application, such as pattern recognition, function approximator or data classification through a learning process. They are made up of simple processing units, which are linked by weighted connections to form structure that are able to learn relationship between sets of variables [6]

Lack of information and data especially in the third world has compounded the problem of workers job satisfaction. This call for a detailed ergonomic study of the activities in the work stations of the ICT to ameliorate this problem, Also, of concern is the near absence of appropriate modeling techniques for determination of worker's job satisfaction using known parameter of health safety, ergonomics and environment (HSEE) in ICT industries. Edosom [8] reported a case study that examined the impact of certain ergonomic factors on the productivity and job satisfaction in a computeraided printed circuit board assembly task. Participative standard with feedback condition emerges as the optimum strategy for improving worker satisfaction and job attitude in a repetitive industrial production task was investigated by [9]. Also, the relationships between personality, team processes, task characteristics, product quality and satisfaction in software development teams were investigated [10]. Most previous studies have essentially used simple approaches such as causal models, simple surveys and statistical methods to investigate job satisfaction. This study however presents an effective algorithm to determine the impacts of HSEE factors on job satisfaction of ICT Directorate of the University of Agriculture Makurdi. The study considers the interaction of HSE and ergonomic factors with respect to job satisfaction by an intelligent algorithm and goes on to propose an artificial neural network (ANN) algorithm for measuring and improving job satisfaction among workers with respect to HSEE.

\section{MATERIALS AND METHODS}

\subsection{Modeling of Job Satisfaction}

An integrated algorithm proposed by [10] was employed to estimate and predict job satisfaction with respect to HSEE (health, safety, environment and ergonomic). The algorithm was the combination of questionnaire, statistical analysis, mathematical models and Artificial Neural Network (ANN) models;

\subsection{Collection of Data and Analysis}

This objective was achieved by use of questionnaires distributed to the 40 workers at the ICT department and the questionnaire contained vital information related to human factors, safety, environment and ergonomics. The score (weight) to each question was assigned between 0 and 1 that show the initial data from the questionnaire. The first questionnaire includes questions about pain and anthropometric issues after daily work. The second set of questions was about Health and the third set of questions was about safety, personal protection items. The fourth set of questions was about temperature of work area, ventilation, noise and lastly set of questionnaire includes questions about ergonomic factors. The input indicators were divided into four main categories which were health, safety, environment, and ergonomic and Job satisfaction as the output as shown in Table1.

\subsection{Determination of Inputs and output}

There were four main input categories (health, safety, environment, ergonomic) as input variables. Then, for each category, the average score was used in the proposed ANN algorithm. The questions that were used as inputs are presented in Table 1 [6]. In addition, one main question was selected from the questionnaire as the output variable, namely, job satisfaction. The output question was stated as follows: "Are you satisfied with your job? " The answer was selected as yes, no or I don't know. The data in were converted to a discrete range of 1 and 2 (instead of $0,0.5$ and 1 for no, I don't know and yes respectively) to eliminate zero from calculations [11]. For each category (health, safety, environment, ergonomic), the average scores were used as the final scores in the algorithm.

\subsection{ANN Modeling}

The relationship of the influence of these inputs parameters HSEE against the output parameter job satisfaction was presented in Figure 1. Trial and error was used to find the best network's architecture that corresponds with inputs/output; since neural network's architecture and learning algorithm are always unknown in advance. The following networks architectures were investigated using Graphical Unit Interface (GUI) of artificial neural network (ANN) found in MATLAB 7.9.0 (R20096); (i) one layered network 6[3]1 1, 4 [2]1 1 (ii) two layered network 4 [5-3]2 1, 4 [3-2]2 1 (iii) three layered network 4 [5-3-2]3 1, 4 [6-3-2]3 1. The above networks architecture were trained using the following algorithms; Scale conjugate gradient (SCG), Gradient decent back propagation (GD), Gradient descent with momentum back propagation (GDM), Gradient descent with momentum and adaptive learning rule back propagation (GDX), LevenbergMarquard (LM), Bayesian Regulation (BR), Resilient Backpropagation (RP). The sigmoid function and linear function were employed between the input and the hidden layers respectively.

Scale conjugate gradient (SCG), neural network model architecture of SCG 4 [3-3]2 1 (4 neurons in the input layer, 2 hidden layers of 3 neurons each and an output layer of 1 neuron) was selected for the modeling of worker's job satisfaction against HSEE after several training with different network architecture and algorithm mentioned earlier. The neural model SCG 4[3-3]2 1, was chosen among the model due to the highest correlation coefficient for both training and testing compared with the other architecture and algorithms presented in Table 2. 
Table 1. The health, safety, environment and ergonomic question used as input indicators.

\begin{tabular}{|l|l|l|l|}
\hline Health & Safety & Environment & Ergonomics \\
\hline & & & \\
\hline $\begin{array}{l}\text { Do you drink enough } \\
\text { water } \\
\text { in hot season? }\end{array}$ & $\begin{array}{l}\text { Do you think it is necessary to use } \\
\text { personal protection items at } \\
\text { work? }\end{array}$ & $\begin{array}{l}\text { Is your work area Temperature } \\
\text { above26 } 6^{0} \mathrm{C} \text { ? }\end{array}$ & $\begin{array}{l}\text { Do you feel any backache after your } \\
\text { daily work? }\end{array}$ \\
\hline $\begin{array}{l}\text { Do pollutants such as } \\
\text { dust exist in your work } \\
\text { environment? }\end{array}$ & $\begin{array}{l}\text { Would there be any circumstance } \\
\text { under which you would have to } \\
\text { ignore safety measures? }\end{array}$ & $\begin{array}{l}\text { Is there sufficient air flow in your } \\
\text { work area? }\end{array}$ & $\begin{array}{l}\text { Is there sufficient space for free } \\
\text { movement in your work space? }\end{array}$ \\
\hline & $\begin{array}{l}\text { Is there any possibility for } \\
\text { accidents which have been } \\
\text { considered in the safety } \\
\text { procedures? }\end{array}$ & $\begin{array}{l}\text { Does noise bother you in your } \\
\text { work area? }\end{array}$ & $\begin{array}{l}\text { Do you feel any pain in your neck or } \\
\text { anywhere after or during work? }\end{array}$ \\
\hline & \multicolumn{1}{|c|}{$\begin{array}{l}\text { Is the working area well } \\
\text { illuminated? }\end{array}$} & $\begin{array}{l}\text { Do you feel pain in your eyes in your } \\
\text { daily work activities? }\end{array}$ \\
\hline
\end{tabular}



Fig 1: Neural network architecture for the modelling of job satisfaction

Table 2: Summary of trained ANN architectures and algorithm used

\begin{tabular}{|c|c|c|}
\hline Architecture & $\begin{array}{l}\text { Correlation } \\
\text { Training } \\
\end{array}$ & $\begin{array}{l}\text { Coefficient (R) } \\
\text { Testing } \\
\end{array}$ \\
\hline Levenberg-Marquard, LM $6[3]_{1} \mathbf{1}$ & 0.7153 & 0.6805 \\
\hline Bayesian Regulation, BR $4[2]_{1} \mathbf{1}$ & 0.9027 & 0.7890 \\
\hline Gradient decent back propagation, GD $4[5-3]_{2} \mathbf{1}$ & 0.4790 & 0.6041 \\
\hline $\begin{array}{l}\text { Gradient descent with momentum and adaptive learning rule back propagation (GDX), } 4 \\
{[5-3-2]_{3} \mathbf{1}}\end{array}$ & 0.742 & 0.9999 \\
\hline Scale conjugate gradient, SCG $4\left[[3-3]_{2} 1\right.$ & 0.97941 & 0.9901 \\
\hline $\begin{array}{l}\text { Gradient descent with momentum back propagation } \\
\text { GDM,5 }[6-3-2]_{3} \mathbf{1}\end{array}$ & 0.806 & 0.752 \\
\hline Resilient Back propagation, RP. $4[6-3]_{2} \mathbf{1}$ & 0.8886 & 0.5739 \\
\hline
\end{tabular}




\subsubsection{Determination of outliers}

The normal probability plot for the 40 workers investigated was obtained in order to identify the outlier's workers following the steps below [6]:

(a) Ordering the efficiency from the largest to the smallest

(b) Numbering the ordered values $i=1,2, \ldots, n$. where the largest value was numbered 1 and the smallest was numbered $n$

(c) Computation of $\mathrm{p}_{\mathrm{i}}=(\mathrm{I}-0.5) / \mathrm{n}$, for $\mathrm{i}=1,2, \ldots, \mathrm{n}$.]

(d) The Table of normal distribution was used to obtain z-values corresponding to the cumulative probability p_i described in step (iii) above,

(e) The probability plot of z-value vs job satisfaction was done

\section{RESULTS AND DISCUSSION}

\subsection{Modeling of Job satisfaction}

The prediction of job satisfaction was done using the neural model SCG 4 [3-3] 1 after series of training as presented in Table 2. The Table 3 also shows statistical analysis that was used in validating the model. The statistical indicators used for validation of the neural network model for prediction of job satisfaction were Error $\left(\mathrm{E}_{\mathrm{i}}\right)$. It was observed that the $\mathrm{E}_{\mathrm{i}}$ values for the prediction of job satisfaction varied in the range of -0.48 to 0.08 . The statistical indicators show that the prediction of job satisfaction employing ANN was satisfactory, and $\mathrm{E}_{\mathrm{i}}$ being reasonably low. The prediction of $1.98,2.00$, and 2.02 at real values of $2.00,2.00$, and 2.00 predicted more accurately than other real values of job satisfaction with $\mathrm{E}_{\mathrm{i}}=0.02,0.00$ and -0.02 . The slight disparity in some of the predicted and real values could be attributed to errors due to misinformation given by some of the respondent.

Also, the quality of the prediction of job satisfaction using ANN models was compared with the real values as shown in Figure 2, taking into cognizance the following point; the quality of prediction of job satisfaction with the number of workers. The visual comparison of the predicted and real job satisfaction showed that the values of predicted job satisfaction by ANN model matched better with the real values. Hence, the visual checking of predicted and real job satisfaction confirms that the ANN model was good in predicting job satisfaction. Table 3 also, shows the efficiency of the 40 workers used for predicting job satisfaction and the efficiency for the workers were ranked according to their efficiency scores.

\subsection{Identification of outliers}

The normal probability plot for the 40 workers was plotted as shown in Figure 6. This was done to identify the outlier or inefficient workers with respect to job satisfaction and HSEE. As indicated on the figure, a number of workers were identified as outliers as some of the plotted points fell far away from the straight line at the lower left corner and the top. This requires that the management should take proper corrective measures to these workers and this confirmed the earlier studies reported by [6] and [11]. Azadeh et al, [5], reported that several reasons could be attributed to existence of outliers. That some of these workers might not have good knowledge of Health, Safety and Environment (HSE) and need to have on-the-job training courses. A few might have answered the questions incorrectly due to job insecurity. The management should provide means to investigate assignable causes that have provided this inefficiency among several workers with respect to Health, Safety, Environment and Ergonomics (HSEE). Workers 3, 9, 14, 17, 18, 23, 28, 32, and 38 were identified as outlier workers. Therefore, 9 workers were not satisfied with their jobs with respect to Health, Safety, Environment (HSE) and ergonomics factors. Corrective actions should be taken by the management to resolve the issue.

\section{CONCLUSION}

The modeling of job satisfaction considering influence of relevant factors such as health, safety, environment and ergonomics was successful. It was shown that the computerbased model provided by ANN predicted values of job satisfaction well compared to the real values as indicated by the statistical indicators used for the validation of the model. The neural network architecture $4[3-3]_{2} \mathbf{1}$ was the best for the prediction of job satisfaction. The normal probability plot was able to identify outliers or inefficient workers. The existence of the outliers showed that some workers were not satisfied with existing Health, safety, Environment (HSE) and Ergonomics (E) programs and calls for improvement. Health, Safety, Environment (HSE) and Ergonomics program play important role not only in enhancement of safety, human and organizational productivity, but it can also be utilized as a tool for recruiting new employees efficient into the organization.

Table 3: Job satisfaction with estimated workers efficiency

\begin{tabular}{|l|l|l|l|l|l|l|}
\hline $\begin{array}{l}\text { Worker's } \\
\text { Code }\end{array}$ & $\begin{array}{l}\text { Real job } \\
\text { Satisfaction }\end{array}$ & $\begin{array}{l}\text { Predicted job } \\
\text { satisfaction }\end{array}$ & $\begin{array}{l}\text { Error } \\
\left(\mathbf{E}_{\mathbf{i}}\right)\end{array}$ & Efficiency, $\left(\mathbf{F}_{\mathbf{i}}\right)$ & Rank & $\begin{array}{l}\text { Z- } \\
\text { values }\end{array}$ \\
\hline 1 & 2.00 & 2.00 & 0.00 & 0.96 & 4 & 1.36 \\
\hline 2 & 2.00 & 1.98 & 0.02 & 0.97 & 3 & 1.53 \\
\hline 3 & 1.50 & 1.69 & -0.19 & 0.87 & 8 & 0.89 \\
\hline 4 & 1.00 & 1.00 & 0.00 & 0.96 & 4 & 1.36 \\
\hline 5 & 1.50 & 1.49 & 0.01 & 0.97 & 3 & 1.53 \\
\hline 6 & 2.00 & 1.98 & 0.02 & 0.97 & 3 & 1.53 \\
\hline 7 & 2.00 & 2.00 & 0.00 & 0.96 & 4 & 1.36 \\
\hline 8 & 2.00 & 2.00 & 0.00 & 0.96 & 4 & 1.36 \\
\hline 9 & 1.50 & 1.98 & -0.48 & 0.73 & 9 & 0.80 \\
\hline 10 & 1.50 & 1.50 & 0.00 & 0.96 & 4 & 1.36 \\
\hline 11 & 2.00 & 1.98 & 0.02 & 0.97 & 3 & 1.53 \\
\hline 12 & 1.50 & 1.50 & 0.00 & 0.96 & 4 & 1.36 \\
\hline
\end{tabular}


International Journal of Applied Information Systems (IJAIS) - ISSN : 2249-0868

Foundation of Computer Science FCS, New York, USA

Volume 11 - No. 11, March 2017-www.ijais.org

\begin{tabular}{|c|c|c|c|c|c|c|}
\hline 13 & 1.50 & 1.50 & 0.00 & 0.96 & 4 & 1.36 \\
\hline 14 & 1.50 & 1.42 & 0.08 & 1.01 & 1 & 2.24 \\
\hline 15 & 2.00 & 2.00 & 0.00 & 0.96 & 4 & 1.36 \\
\hline 16 & 2.00 & 1.98 & 0.02 & 0.97 & 3 & 1.53 \\
\hline 17 & 1.00 & 1.02 & -0.02 & 0.94 & 6 & 1.09 \\
\hline 18 & 1.50 & 1.64 & -0.14 & 0.88 & 7 & 0.98 \\
\hline 19 & 1.50 & 1.50 & 0.00 & 0.96 & 4 & 1.36 \\
\hline 20 & 2.00 & 1.98 & 0.02 & 0.97 & 3 & 1.53 \\
\hline 21 & 2.00 & 2.00 & 0.00 & 0.96 & 4 & 1.36 \\
\hline 22 & 1.50 & 1.50 & 0.00 & 0.96 & 4 & 1.36 \\
\hline 23 & 1.50 & 1.53 & -0.03 & 0.94 & 6 & 1.09 \\
\hline 24 & 2.00 & 2.00 & 0.00 & 0.96 & 4 & 1.36 \\
\hline 25 & 2.00 & 2.02 & -0.02 & 0.95 & 5 & 1.21 \\
\hline 26 & 1.50 & 1.50 & 0.00 & 0.96 & 4 & 1.36 \\
\hline 27 & 1.50 & 1.50 & 0.00 & 0.96 & 4 & 1.36 \\
\hline 28 & 1.50 & 1.46 & 0.04 & 0.99 & 2 & 1.78 \\
\hline 29 & 1.50 & 1.52 & -0.02 & 0.95 & 5 & 1.21 \\
\hline 30 & 2.00 & 2.00 & 0.00 & 0.96 & 4 & 1.36 \\
\hline 31 & 1.50 & 1.50 & 0.00 & 0.96 & 4 & 1.36 \\
\hline 32 & 1.50 & 1.43 & 0.07 & 1.01 & 1 & 2.24 \\
\hline 33 & 2.00 & 1.98 & 0.02 & 0.97 & 3 & 1.53 \\
\hline 34 & 1.50 & 1.52 & -0.02 & 0.95 & 5 & 1.21 \\
\hline 35 & 2.00 & 2.03 & -0.03 & 0.95 & 5 & 1.21 \\
\hline 36 & 1.50 & 1.50 & 0.00 & 0.96 & 4 & 1.36 \\
\hline 37 & 1.50 & 1.51 & -0.01 & 0.96 & 4 & 1.36 \\
\hline 38 & 2.00 & 2.04 & -0.04 & 0.94 & 6 & 1.09 \\
\hline 39 & 2.00 & 2.00 & 0.00 & 0.96 & 4 & 1.36 \\
\hline 40 & 1.50 & 1.50 & 0.00 & 0.96 & 4 & 1.36 \\
\hline
\end{tabular}

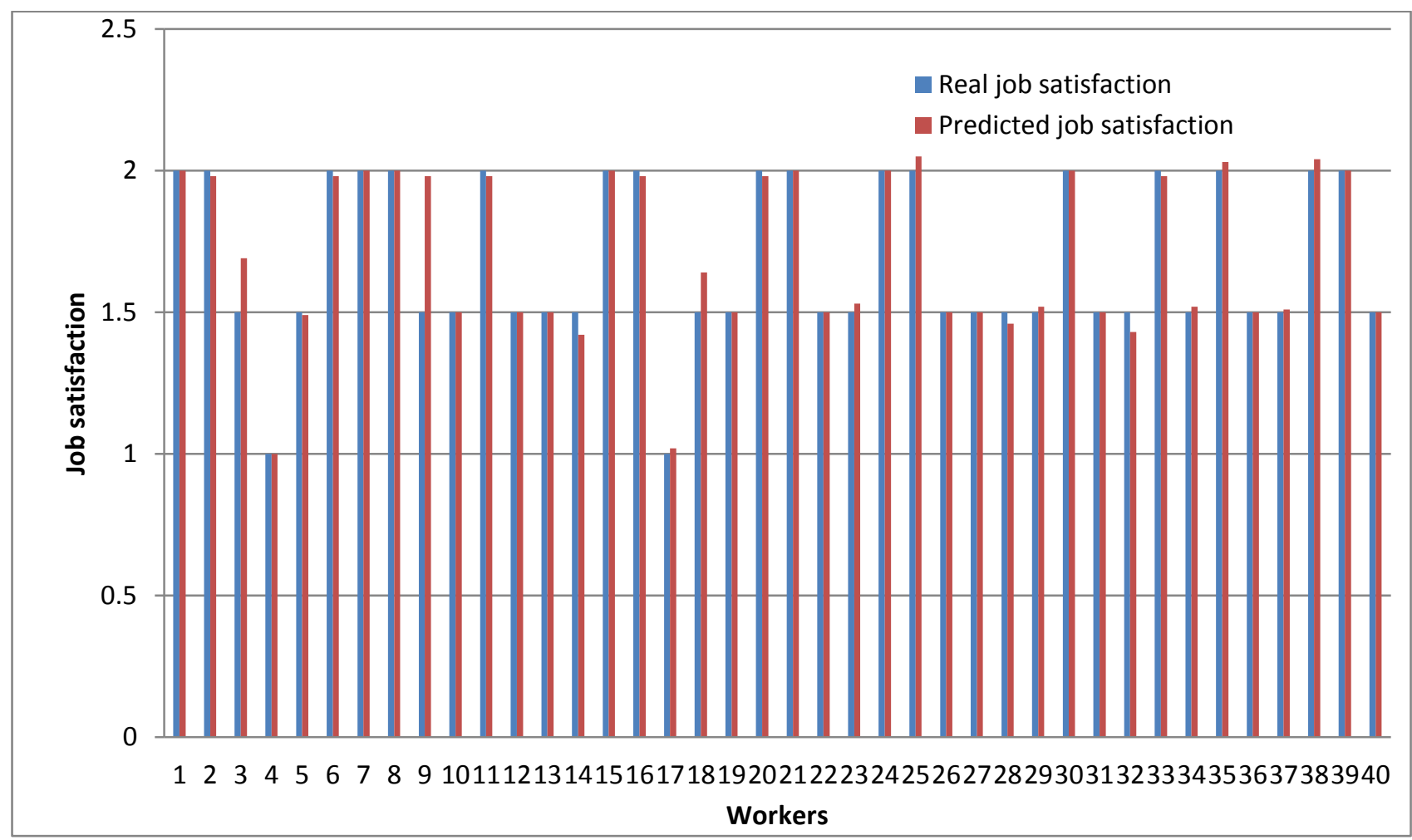

Fig 2: Comparison of the predicted and real job satisfaction 


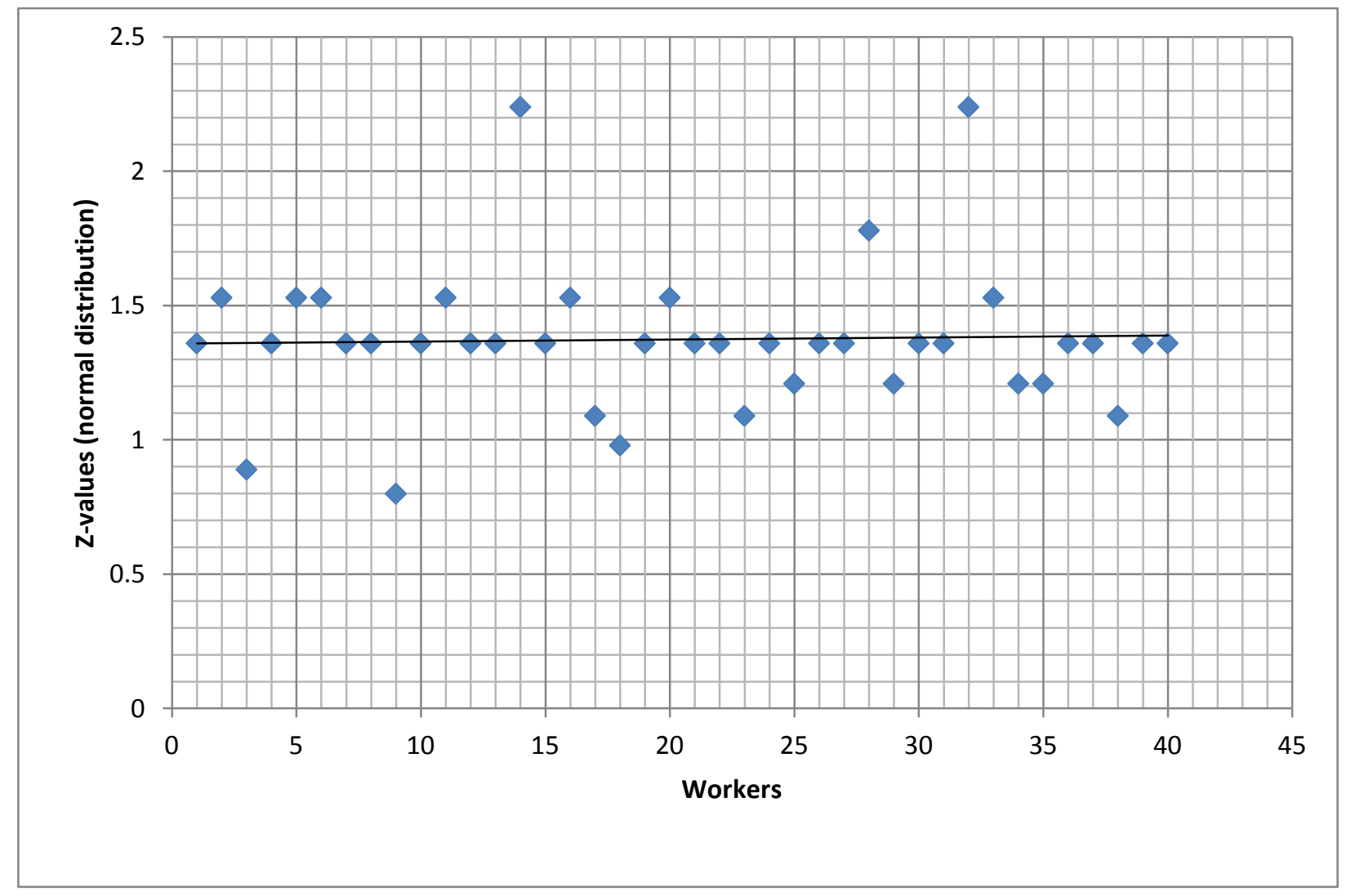

Fig 6: Normal probability plot for efficiency scores of 40 workers

\section{REFERENCES}

[1] Kroemer K.H.E. 2002. Fundamentals ofIndustrial Hygiene. Occupational Health \& Safety Administration Washinton (2002)

[2] Johnson, O. E., Onigbinde, A.T., Onasanya, S.A., Emechete, A.A.I., \& Gbela, T.O. 2008. Assessment of ergonomic workstations and pain among computer users in Nigeria University community. Nigerian journal of medical rehabilitation, 13(21), 34-45

[3] Adedoyin R.A, Idowu B.O, Adagunodo R.E and Idowu P.A. 2004. Musculoskeletal pain associated with the use of Computer system in Nigeria. International Joumal of Pain, Symptoms control and Palliative Care,

ISSN $1528-8277$.

[4] Ragu-Nathan, T.S., Tarafdar, M., Ragu-Nathan, B.S. , Tu, Q. (2008). The consequences of technostress for end users in organizations: Conceptual development and empirical variation. Information System Research. Vol.19(4), 417-433.

[5] Charlse, N.J. (2000). BEACON Biodynamic and Ergonomics Symposium. University of Connecticut Famingtonicom.

[6] Azadeh, A., Rouzbahman, M., Saberi, M., Mohammed Fam, I. 2011. An adaptive neural network algorithm for assessment and improvement of job satisfaction with respect to HSE and ergonomic program: The case of a gas refinery. Journal of Loss Prevention. Vol. 24, 361370 .
[7] Azadeh, A., Mohammed Fam, I., Nouri, M.A. 2008 Integrated health, safety, environment and ergonomic management system (HSE-MS): An efficient substitution for conventional HSE-MS. Journal of Scientific and Industrial Research. Vol. 67, 403-411.

[8] Edosomw, J.A. 1986. Role of ergonomics in improving job satisfaction on computer-aided Assembly tasks. Proceedings, American institute of industrial engineers, annual conference convention, 378-381

[9] Shikdar, A.A., Das, B. (2003). A strategy for improving worker satisfaction and job attitudes in A repetitive industrial task: application of production standards and performance feed back. Ergonomics. Vol.46 (5), 466-481

[10] Acuna, S.T. Gomez, M., Juristo, N. (2009). How do personability, team processes and task characteristics relate to job satisfaction. Journal of Information and Software. Vol. 51 (3), 627-639.

[11] Azadeh, A., Rouzbahman, M., Saberi, M., Valianpour, F.,Keramati, A. (2013).Improved Prediction of mental workload versus HSE and ergonomics factors by an adaptive intelligent algorithm. Safety Science. Vol. 58, 59-75.

[12] Azadeh, A., Rouzbahman, M., Saberi, M., Valianpour, F.,Keramati, A. 2013.Improved Prediction of mental workload versus HSE and ergonomics factors by an adaptive intelligent algorithm. Safety Science. Vol. 58, 